\title{
Electron Transfer Through H-bonded Peptide Assemblies
}

Heinz-Bernhard Kraatz, * Irene Bediako-Amoa, Samuel H. Gyepi-Garbrah and Todd. C. Sutherland

Department of Chemistry, University of Saskatchewan, 110 Science Place, Saskatoon, Saskatchewan, CANADA S7N 5C9. kraatz@ skyway.usask.ca

\section{Supporting Information}

1

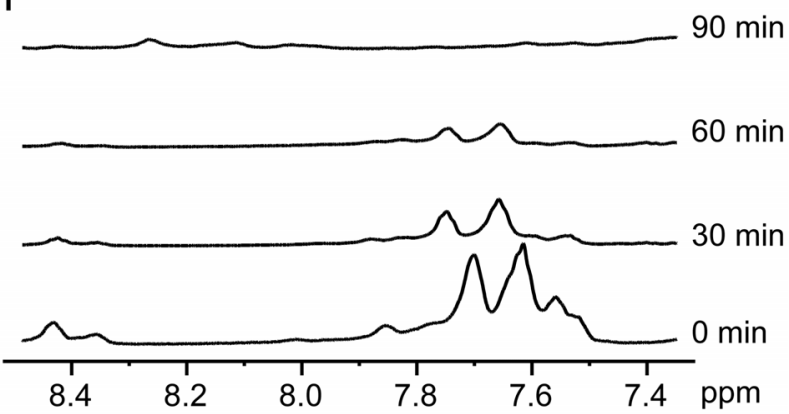

3

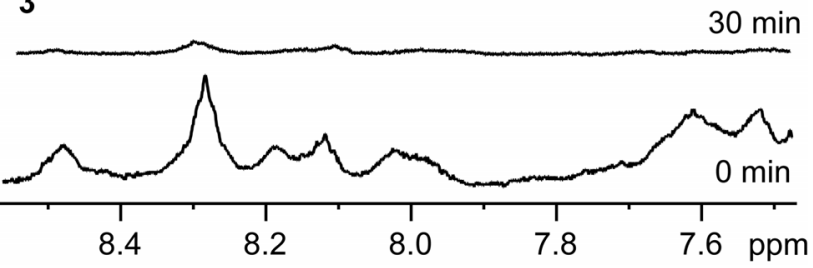

Figure 1. Expanded portion of the Amide A region showing exchange of $\mathrm{N}-\mathrm{H}$ signal due to for Fc-peptide conjugates $\mathbf{1}$ and $\mathbf{3}$. A drop of $\mathrm{D}_{2} \mathrm{O}$ was added to $\mathrm{CDCl}_{3}$ solutions of $\mathbf{1}$ and $\mathbf{3}$. For 1, the H/D exchanged occurred at room temperature over a 90 minute period. Whereas, peptides $\mathbf{2}$ and $\mathbf{3}$ required heating of the sample at $58{ }^{\circ} \mathrm{C}$ for 30 minutes to obtain complete $\mathrm{H} / \mathrm{D}$ exchange.

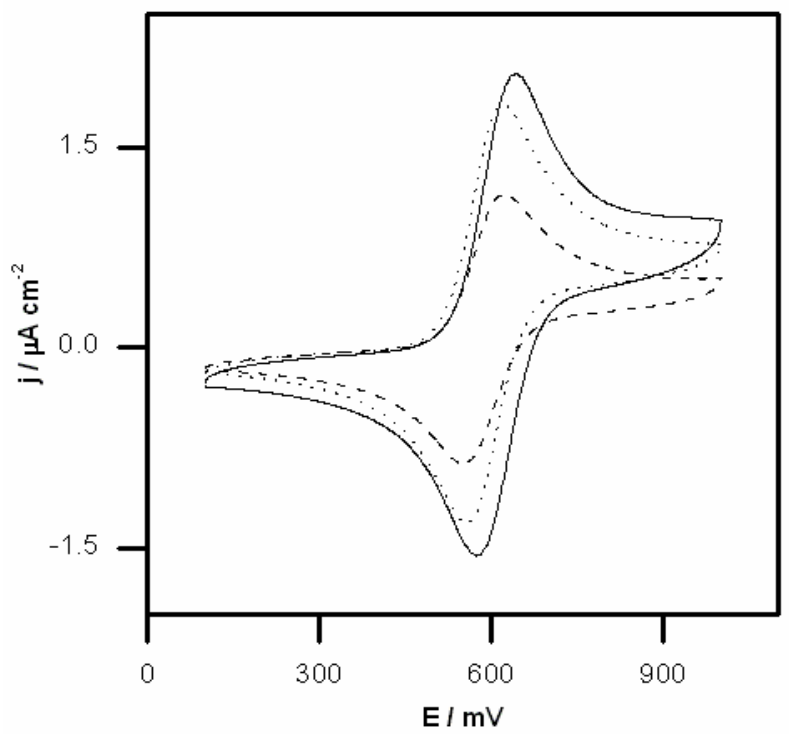

Figure 2. Solution electrochemistry of FcPeptides 1 - 3 in $0.1 \mathrm{M}$ TBAP/CH${ }_{3} \mathrm{CN}$ at a Scan rate of $100 \mathrm{mV} \cdot \mathrm{s}^{-1} \mathbf{1}(), \mathbf{2}(), \mathbf{3}()$. 


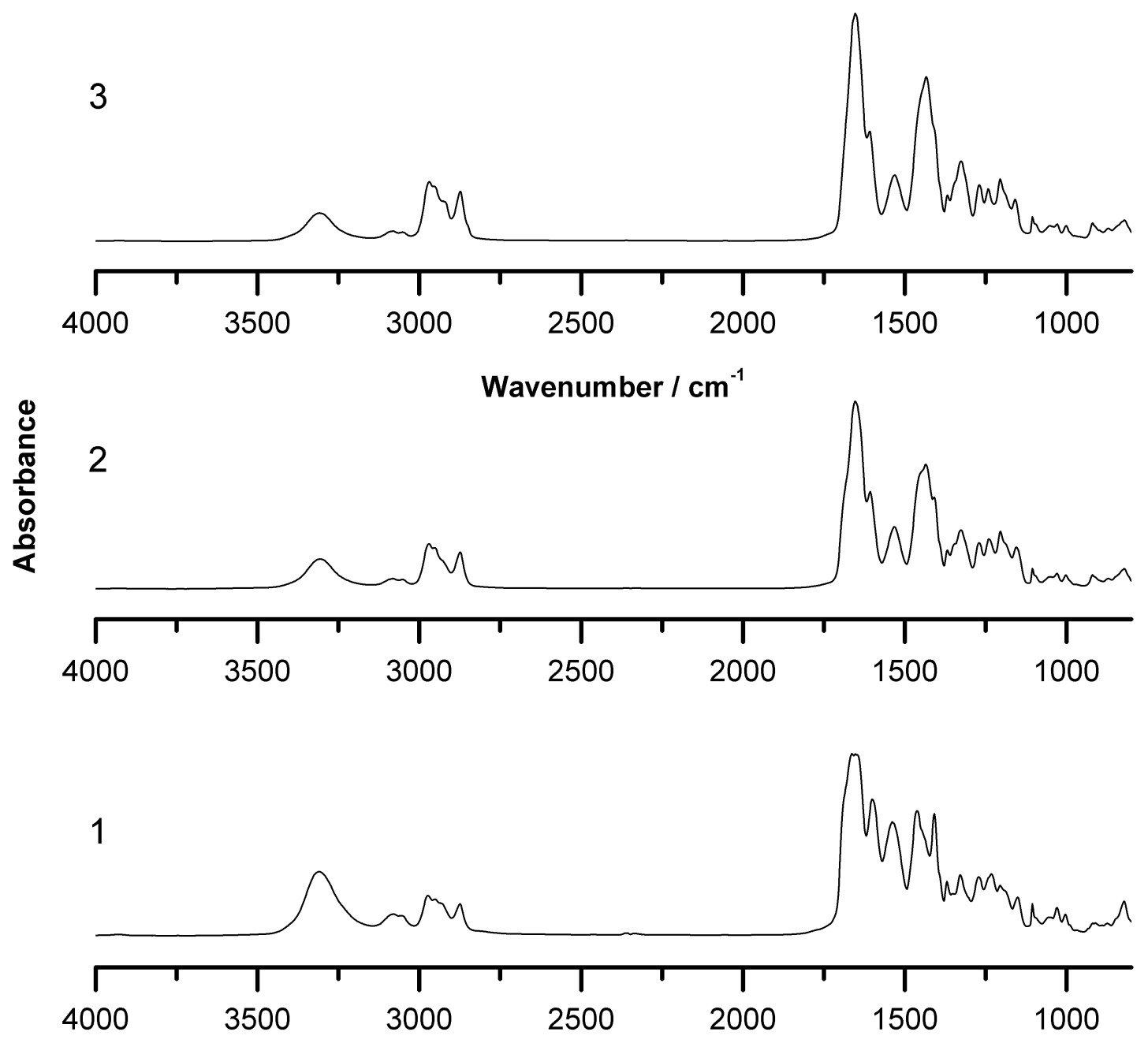

Figure 3. IR spectra (KBr) of peptide $\mathbf{1}-\mathbf{3}$. 


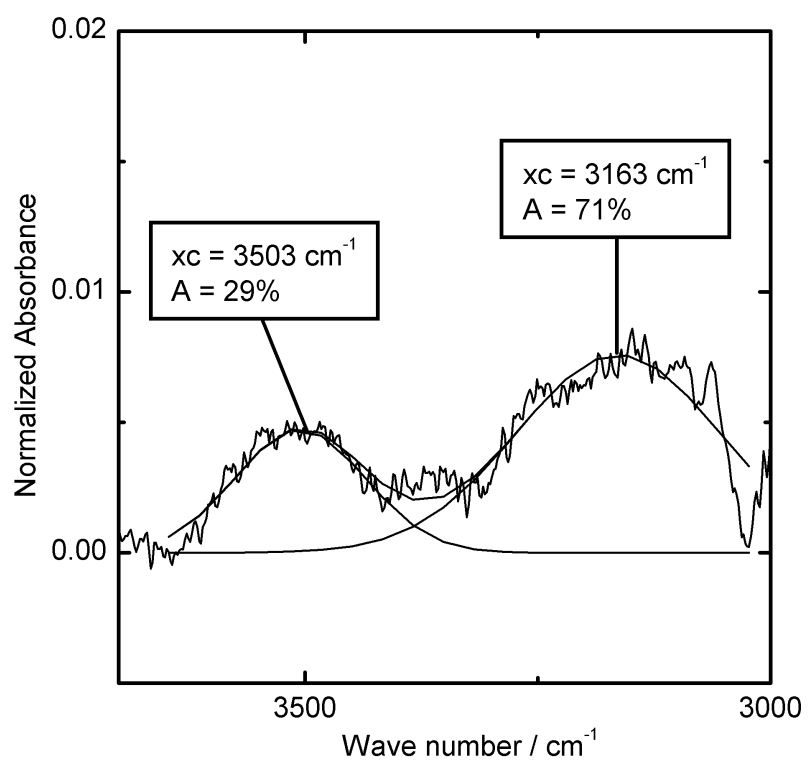

Figure 4. RAIRS of the Amide A region of $\mathbf{1}$.

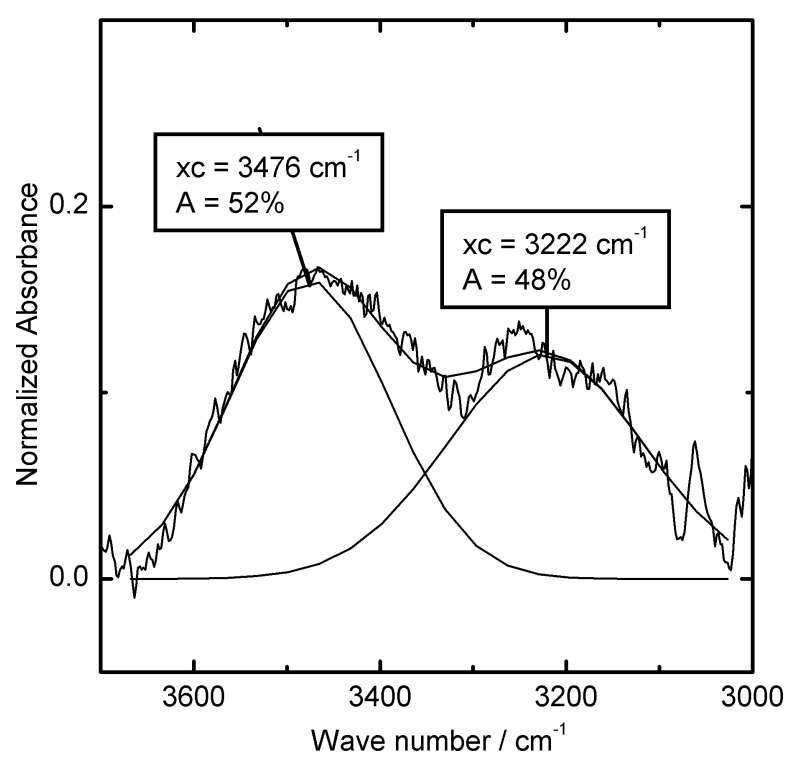

Figure 6. RAIRS of the Amide A region of $\mathbf{3}$.

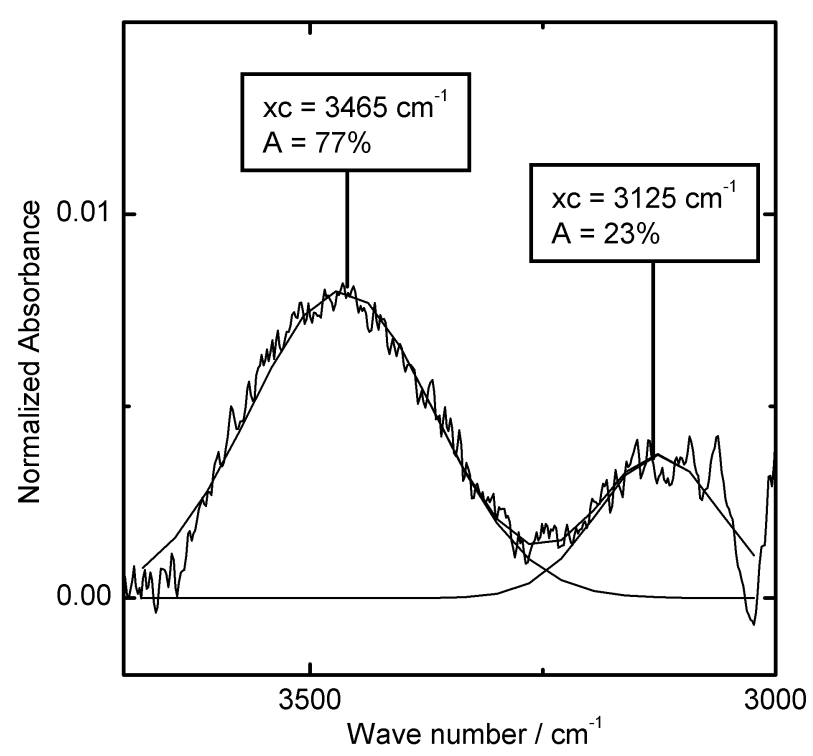

Figure 5. RAIRS of the Amide A region of 2. 
Peptide tilt angles calculation by RAIRS.

$D_{o b s}=\frac{I_{1}}{I_{2}}=C\left(\frac{2\left[\frac{1}{2}\left(3 \cos ^{2} \gamma-1\right) \cdot \frac{1}{2}\left(3 \cos ^{2} \theta_{1}-1\right)\right]+1}{2\left[\frac{1}{2}\left(3 \cos ^{2} \gamma-1\right) \cdot \frac{1}{2}\left(3 \cos ^{2} \theta_{2}-1\right)\right]+1}\right)$

$D_{o b s}$ represents the observed ratio of Amide I and Amide II absorbances and $\gamma, \theta_{i}$ and $\mathrm{C}$, the tilt angle of the peptide axis from the surface normal, the angle between the transition moment (amide I amide II) and the helix axis, and the scaling constant, respectively. In case of helical peptides the transition moment from the helix axis is reported as $39^{\circ}$ of $\theta_{1}$ and $75^{\circ}$ of $\theta_{2}$, respectively. ${ }^{1,2}$ The scaling factor, $C$, can be determined from the ratio of Amide I and Amide II absorbance in a $\mathrm{KBr}$ pellet as an approximation of a random orientation. As reported in the literature ${ }^{3}$ for peptidic monolayers the scaling factor is approximated to $1.5^{4-6}$

\section{Collagen melting temperature determination.}

Fc-peptides 1, 2 and $\mathbf{3}$ were fit to the following general sigmoid curve shape using the following formula:

$$
y=A_{2}+\frac{A_{1}-A_{2}}{1+e^{-(x-x c) / d x}}
$$

where $A_{2}$ is the fully $\mathrm{H}$-bonded system and $A_{1}$ is the melted peptide. $d x$ is a parameter that accommodates the steepness of the sigmoid and $x_{\mathrm{c}}$ is the melting temperature. Residuals were minimized using the Levenberg-Marquardt algorithm built into Origin 7.0 (OriginLab Corporation, Northampton, MA, USA). 
Table 1. Parameters from $\mathrm{CV}$ of the Concentrated and Mixed Monolayers of Fc-peptides in $2 \mathrm{M} \mathrm{NaClO}_{4} \mathrm{H}_{2} \mathrm{O} / \mathrm{D}_{2} \mathrm{O}$.

\begin{tabular}{ccccr}
\hline Compound & \multicolumn{2}{c}{$\Delta \boldsymbol{E}(\mathbf{m V})$} & \multicolumn{2}{c}{$\begin{array}{c}\Delta \boldsymbol{E}_{\text {fwhm }} \\
(\mathbf{m V})\end{array}$} \\
& \multicolumn{1}{c}{$\mathrm{H}_{2} \mathrm{O}$} & \multicolumn{1}{c}{$\mathrm{D}_{2} \mathrm{O}$} & \multicolumn{1}{c}{$\mathrm{H}_{2} \mathrm{O}$} & \multicolumn{1}{c}{$\mathrm{D}_{2} \mathrm{O}$} \\
\hline $\mathbf{1}$ & $35(10)$ & $60(18)$ & $145(8)$ & $126(16)$ \\
$\mathbf{2}$ & $40(7)$ & $40(15)$ & $140(12)$ & $110(10)$ \\
$\mathbf{3}$ & $45(10)$ & $40(15)$ & $150(15)$ & $110(10)$ \\
$\mathbf{1}^{\mathrm{a}}$ & $40(12)$ & $30(10)$ & $125(15)$ & $95(5)$ \\
$\mathbf{2}^{\mathrm{a}}$ & $36(15)$ & $25(10)$ & $120(20)$ & $110(10)$ \\
$\mathbf{3}^{\mathrm{a}}$ & $40(10)$ & $50(11)$ & $130(10)$ & $128(15)$ \\
\hline
\end{tabular}

${ }^{a}$ mixed monolayers of Fc-Peptides using hexanethiol

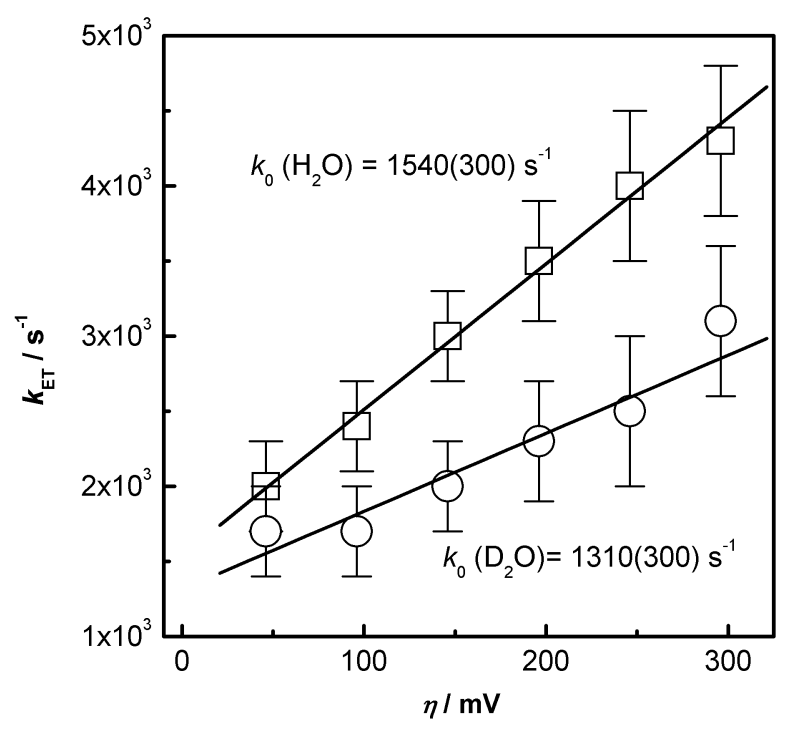

Figure 7. CA results for the calculation of $k_{\mathrm{ET}}$ for compound 3 in $\mathrm{H}_{2} \mathrm{O}$ and $\mathrm{D}_{2} \mathrm{O}$.
Impedance CNLS fitting: The curve fitting was done using ZSimpWin software (v2.00). All parameters were permitted to float during the curve fitting process. The resultant model chosen (see Figure 4 of main text) has a $\chi^{2}$ value of 0.002 on a typical data set. Of course inclusion of additional parameters resulted in a slightly lower $\chi^{2}$ value( 0.001$)$. However, we have chosen to follow the general rule that addition of a parameter should result in a 10 fold decrease in $\chi^{2}$ value. Equivalent circuit models that contained 4 or fewer parameters resulted in an 8-15 fold increase in $\chi^{2}$ value.

\section{References}

(1) Tsuboi, M. J. Polym. Sci. 1965, 59, 139.

(2) Kimura, S.; Miura, Y.; Morita, T.; Kobayashi, S.; Imanashi, Y. J. Polym. Sci. Part A: Polym. Chem. 2000, 38, 4826.

(3) Worley, C. G.; Linton, R. W.; Samulski, R. W. Langmuir 1995, 11, 3805.

(4) Miura, Y.; Kimura, S. Langmuir 1999, 15, 1155.

(5) Erniquez, E. P.; Gray, K. H.; Guarisco, V. F.; Linton, R. W.; Mar, K. D.; Samulski, E. T. J. Vac. Sci. Technol. 1992, 10, 2775.

(6) Miura, Y.; Kimura, S.; Kobayashi, S.; Imanashi, Y.; Uemura, J. Biopolymers 2000, 55, 391. 